\title{
Correlação entre o número de fêmeas e o número de juvenis de Tylenchulus semipenetrans em amostras de solo e raiz de laranjeira 'Pera Rio' enxertada em limoeiro 'Cravo'
}

\author{
Adriana Aparecida Gabia ${ }^{1,3}$, Thiago Rodrigo Gonçalves dos Santos ${ }^{2}$, Mario Henrique Ferreira do Amaral Dal \\ Pogetto $^{1}$, Silvia Renata Siciliano Wilcken ${ }^{1}$.
}

${ }^{1}$ Departamento de Proteção Vegetal, Faculdade de Ciências Agronômicas, Campus de Botucatu, SP, CEP: $18.610-307 .{ }^{2}$ Louis Dreyfus Commodities Agroindustrial S.A, Bebedouro, SP; ${ }^{3}$ Bolsista Capes. Parte da Dissertação de Mestrado do primeiro autor.

Autores para correspondência: Adriana Aparecida Gabia (adrianagabia@hotmail.com); Silvia Renata Siciliano Wilcken (srenata@fca.unesp.br). Data de chegada: 15/04/2013. Aceito para publicação em: 03/03/2015.

$10.1590 / 0100-5405 / 1884$

\section{RESUMO}

Gabia, A.A.; Santos, T.R.G.; Dal Pogetto, M.H.F.A.; Wilcken, S.R.S. Correlação entre o número de fêmeas e o número de juvenis de Tylenchulus semipenetrans em amostras de solo e raiz de laranjeira 'Pera Rio' enxertada em limoeiro 'Cravo'. Summa Phytopathologica, v.41, n.2, p.121$125,2015$.

Várias espécies de fitonematoides já foram relatadas em pomares de citros, porém poucas são consideradas praga-chave para a cultura. No Brasil, Tylenchulus semipenetrans é o principal nematoide em citros, amplamente disseminado nos pomares brasileiros. Diferentes variáveis são utilizadas para determinar o nível de dano desse nematoide. Sendo assim, esse experimento teve por objetivo correlacionar o número de fêmeas com o número de juvenis de T. semipenetrans em amostras de solo e raiz de laranja 'Pera Rio' enxertada em limoeiro 'Cravo'. O trabalho foi realizado em pomar de 14 anos, localizado na Fazenda São Gabriel, distrito de Vitoriana, município de Botucatu - SP. A coleta das amostras foi realizada em setembro de 2011, numa profundidade de 0-30 $\mathrm{cm}$, em 10 plantas sem sintomas, $10 \mathrm{com}$ sintomas e as adjacentes das plantas sintomáticas, totalizando 60 plantas. Para extração dos nematoides presentes no solo seguiu-se a metodologia de flutuação em centrífuga e para a dos nematoides nas raízes seguiu-se a técnica do liquidificador e centrifugação. Para contagem das fêmeas, $1 \mathrm{~g}$ de raiz de cada amostra foi colorida. Os dados de nematoide no solo, nematoide na raiz, soma de nematoide no solo e raiz e fêmeas por grama de raiz foram submetidos à análise de correlação de Pearson e posteriormente à análise de matriz de correlações. Dentre os dados analisados, pode-se verificar uma forte correlação entre o número de juvenis presentes na raiz e a soma do número de juvenis no solo e na raiz. Entretanto, não foi constatado correlação desta variável com o número de fêmeas na raiz e o número de juvenis no solo. O número de fêmeas na raiz não apresentou correlação com nenhuma das outras variáveis analisadas. Conclui-se que a melhor variável para determinar a população de $T$. semipenetrans é o número de juvenis por $10 \mathrm{~g}$ de raiz.

Palavras-chave: Citrus sinesis, nematoide do citros, nível de dano.

\section{ABSTRACT}

Gabia, A.A.; Santos, T.R.G.; Dal Pogetto, M.H.F.A.; Wilcken, S.R.S. Correlation between the number of females and the number of juveniles of Tylenchulus semipenetrans in samples of soil and root of 'Pera Rio' orange trees grafted onto 'Cravo' lemon tree. Summa Phytopathologica, v.41, n.2, p.121-125, 2015.

Several phytonematode species have been reported for citrus orchards, but few are considered key pests for this crop. In Brazil, Tylenchulus semipenetrans is the main nematode of citrus orchards widely spread among the country. Different variables are used to determine the level of damage caused by this nematode. Thus, this experiment aimed to correlate the number of females with the number of juveniles of T. semipenetrans in samples of soil and root from 'Pera Rio' orange grafted onto 'Rangpur' lime. The study was conducted in a 14-year-old orchard, located at São Gabriel Farm, Vitoriana District, Botucatu - SP. Sampling was performed in September 2011 at a depth of 0-30 cm, using 10 plants without symptoms, 10 plants with symptoms and plants adjacent to symptomatic ones, totaling 60 plants. For extraction of the nematodes present in the soil, the methodology of centrifugal flotation was adopted, while for the nematodes in the roots the technique using blender and centrifugation was employed. To count the number of females, $1 \mathrm{~g}$ root of each sample was colored. The data about soil nematode, root nematode, sum of soil and root nematode and females per gram of root were subjected to Pearson's correlation analysis and subsequently to correlation matrix. Considering the analyzed data, there was a strong correlation between the number of juveniles present in the root and the sum of the number of juveniles present in the soil and the root. However, there was no correlation of this variable with the number of females in the root and the number of juveniles in the soil. The number of females in the root was not correlated with any of the other analyzed variables. It is concluded that the best variable to determine the population of $T$. semipenetrans is the number of juveniles per $10 \mathrm{~g}$ of root.

Additional keywords: Citrus sinensis, the citrus nematode, damage level. 
Várias espécies de nematoides fitoparasitas já foram encontradas em pomares citrícolas em todo mundo. Porém, poucas são consideradas problema para a citricultura $(5,6)$. No Brasil, Tylenchulus semipenetrans é considerada uma das espécies mais importantes e se encontra amplamente disseminada pelos pomares $(1,10)$. Esse nematoide é causador do "declínio lento dos citros", doença que provoca desenvolvimento insatisfatório das plantas e consequente redução na produtividade (5).

Cohn (2), em Israel, relatou que populações de 4.000 juvenis de $T$. semipenetrans $/ g$ de raiz foram suficientes para promover o sintoma de declínio lento nas plantas cítricas. Duncan \& Cohn (5), na Califórnia, determinaram que números inferiores a 300, entre 700 e 1.400 e superiores a 1.400 fêmeas/g de raiz representavam níveis baixo, moderado e alto, respectivamente. Os autores não detectaram redução na produção de citros na Flórida quando a população estava abaixo de 2.000 juvenis por $100 \mathrm{~cm}^{3}$ de solo, mesmo quando as amostras eram coletadas nos períodos de pico da populacão. Porém, quando a amostragem era realizada nos períodos de baixa densidade populacional, o nível de dano econômico estava em torno de 850 juvenis $100 \mathrm{~cm}^{3}$ de solo.

Diferentemente de Duncan \& Cohn (5), Westerdahl (13) sugere o tratamento químico de pomares da Califórnia quando a população de T. semipenetrans estiver acima de 400 fêmeas do nematoide/g de raiz em amostras coletadas nos meses de fevereiro a abril ou 700 fêmeas $/ g$ raiz de maio a junho.

Embora cada estudo tenha encontrado diferentes níveis de dano, deve-se ressaltar as diferenças nas variáveis avaliadas; ora fêmeas por grama/raiz, ora juvenis por grama/raiz ou ainda juvenis por $\mathrm{cm}^{3} /$ solo.

Contudo, no Brasil não há estudos sobre qual a melhor variável para avaliação populacional: número de juvenis no solo ou na raiz, ou número de fêmea na raiz, ou ainda se há correlação entre essas variáveis. Diante desse cenário, esse experimento teve por objetivo correlacionar o número de fêmeas com o número de juvenis de T. semipenetrans em amostras de solo e raiz de laranjeira 'Pera Rio' enxertada em limoeiro 'Cravo'.

\section{MATERIAL E MÉTODOS}

\section{Local de execução do experimento em campo}

O trabalho foi realizado em pomar de 14 anos, formado com a variedade 'Pera Rio' [Citrus sinensis (L.) Osbeck], enxertada em limoeiro 'Cravo' (Citrus limonia Osbeck), com histórico de infestação de T. semipenetrans, localizado na Fazenda São Gabriel, distrito de Vitoriana, município de Botucatu - SP, situado a $22^{\circ} 43^{\text {' }}$ $80,1^{\prime \prime S}$ e 48²0'02,3"W, com altitude de $530 \mathrm{~m}$. O clima da região é classificado como Cwa de acordo com sistema de Köppen (11), com índice pluviométrico anual de 1.850,0 $\mathrm{mm}$, distribuídos de outubro a abril e estação seca de maio a setembro. A temperatura média anual é de $21,2^{\circ} \mathrm{C}$.

\section{Obtenção das amostras}

A coleta das amostras de solo e raiz foi realizada em setembro de 2011, época recomentada para amostragem de Tylenchulus semipenetrans $(1,5)$, numa profundidade de $0-30 \mathrm{~cm}$, na projeção da copa das plantas. Foram selecionadas 10 plantas sem sintomas, 10 com sintomas e as quatro plantas adjacentes das sintomáticas, totalizando 60 plantas. As amostras foram acondicionadas em sacos plásticos, devidamente etiquetados e encaminhadas ao Laboratório de Nematologia do Departamento de Proteção Vegetal da Faculdade de Ciências Agronômicas - UNESP - Campus Botucatu.

\section{Extração de T. semipenetrans}

O processamento para extração dos nematoides presentes no solo foi seguindo a metodologia de flutuação em centrífuga (8), e para a extração dos nematoides nas raízes seguindo a técnica do liquidificador e centrifugação (3). Os nematoides encontrados nas amostras de solo e raiz foram contados e identificados em nível de espécie, em câmara de Peters sob microscópio de luz.

\section{Coloração das raízes e contagem das fêmeas}

Um grama de raiz de cada amostra foi pesado e posteriormente colocado em frascos de vidro com uma solução a base de fucsina ácida e aquecidos, onde permaneceram até levantar fervura (4). Após esfriar, as raízes foram descoloridas, colocadas em placa de Petri e levadas ao miscroscópio estereoscópio para a contagem das fêmea.

\section{Análise dos dados}

Os dados de nematoides no solo, nematoides na raiz, soma de nematoides no solo e raiz e fêmeas por grama de raiz foram submetidos à análise de correlação de Pearson e posteriormente à análise de matriz de correlações, usando o programa estatístico Bioestat.

\section{RESULTADO E DISCUSSÃO}

Foi observado forte correlação entre o número de juvenis presentes na raiz e a soma do número de juvenis presentes no solo e na raiz, seguindo a equação $\mathrm{y}=1,0036 \mathrm{x}+223$, onde $\mathrm{y}=$ soma do número de juvenis presentes no solo e na raiz e $\mathrm{x}=$ número de juvenis em 10 gramas de raiz (Figura 1). Entretanto, não foi observada a correlação entre o número de juvenis encontrados no solo e a soma do número destes no solo e na raiz; e entre o número de juvenis encontrados no solo e na raiz (Figuras 2 e 3 ).

O processamento da raiz permitiu a extração de uma população maior de juvenis do que o processamento de solo. Enquanto que na raiz foi encontrado uma população que variou de 0 a 77.050, no solo a população foi bastante inferior, variando de 0 a 5.832, corroborando Sorribas (12) em que o número de juvenis no solo não é uma boa representação da população presente no campo. Na soma dessas duas variáveis prevaleceu a tendência encontrada na raiz. O número elevado de juvenis encontrados na raiz pode ser justificado devido às características do nematoide, que é ectoparasita sedentário, e que coloca seus ovos em massas gelatinosas aderidas nas raízes (7).

A correlação entre o número de fêmeas na raiz e as demais variáveis estudadas não foi constatada (Figuras 4, 5 e 6). Embora esta variável seja considerada a mais recomendada em estudos sobre a eficácia de nematicida em pomares citrícolas $(5,9)$, por representar a sobrevivência dos juvenis sob a ação do produto, em geral não é obtida em análise de amostras nematológicas de rotina.

Sorribas et al. (12) também consideram esta variável a mais indicada para avaliar a população do nematoide, uma vez que apresenta de dois a três picos populacionais durante o ano.

A correlação entre o número de juvenis na raiz e o número de fêmeas na raiz era esperada, pois um maior número de fêmeas proporciona maior número de descendentes. Entretanto pode ter ocorrido a influência da época da amostragem sob o desenvolvimento do nematoide. Provavelmente quando o número de juvenis se encontra elevado, as fêmeas já se encontram mortas e degeneradas.

A análise nematológica realizada rotineiramente avalia o número de juvenis presentes nas raízes e no solo. Entretanto, o nível de dano de T. semipenetrans é dado, na maioria das vezes, em 
número de fêmeas por grama de raiz $(5,9,12)$. A possibilidade de extrapolar o número de juvenis para o número de fêmeas facilitaria a interpretação dos dados e determinação do nível de dano. No entanto, no presente trabalho, constata-se que em amostragens realizadas no início do mês de setembro essa extrapolação não pode ser feita.

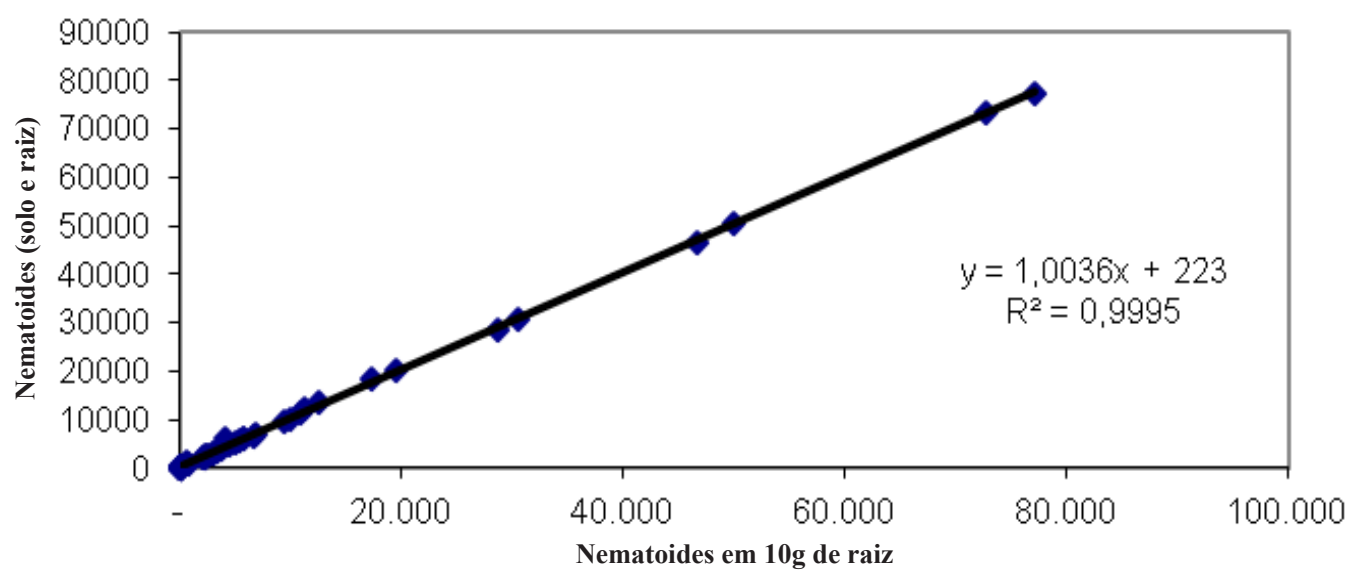

Figura 1. Correlação entre a soma de juvenis de Tylenchulus semipenetrans encontrados em 10 gramas de raiz e $250 \mathrm{ml}$ de solo e o número destes em 10 gramas de raiz, amostras coletadas em setembro de 2011, Botucatu - SP.

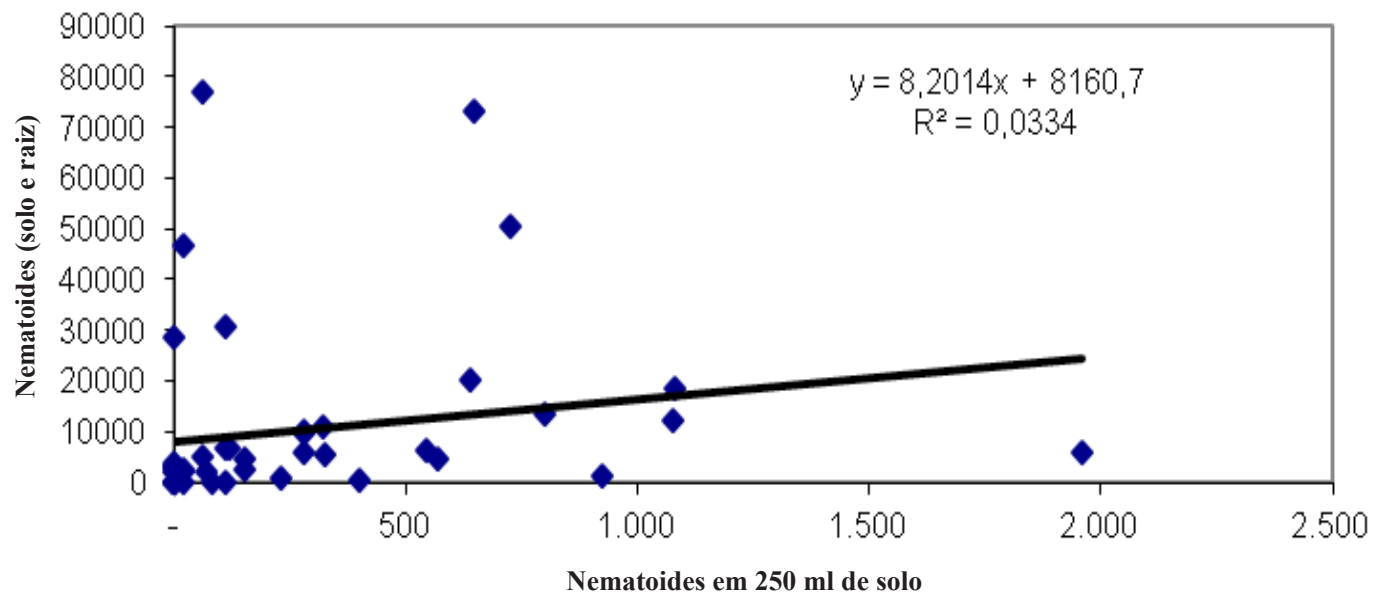

Figura 2. Correlação entre a soma de juvenis de Tylenchulus semipenetrans encontrados em 10 gramas de raiz e $250 \mathrm{ml}$ de solo e o número destes em $250 \mathrm{ml}$ de solo, amostras coletadas em setembro de 2011, Botucatu - SP.

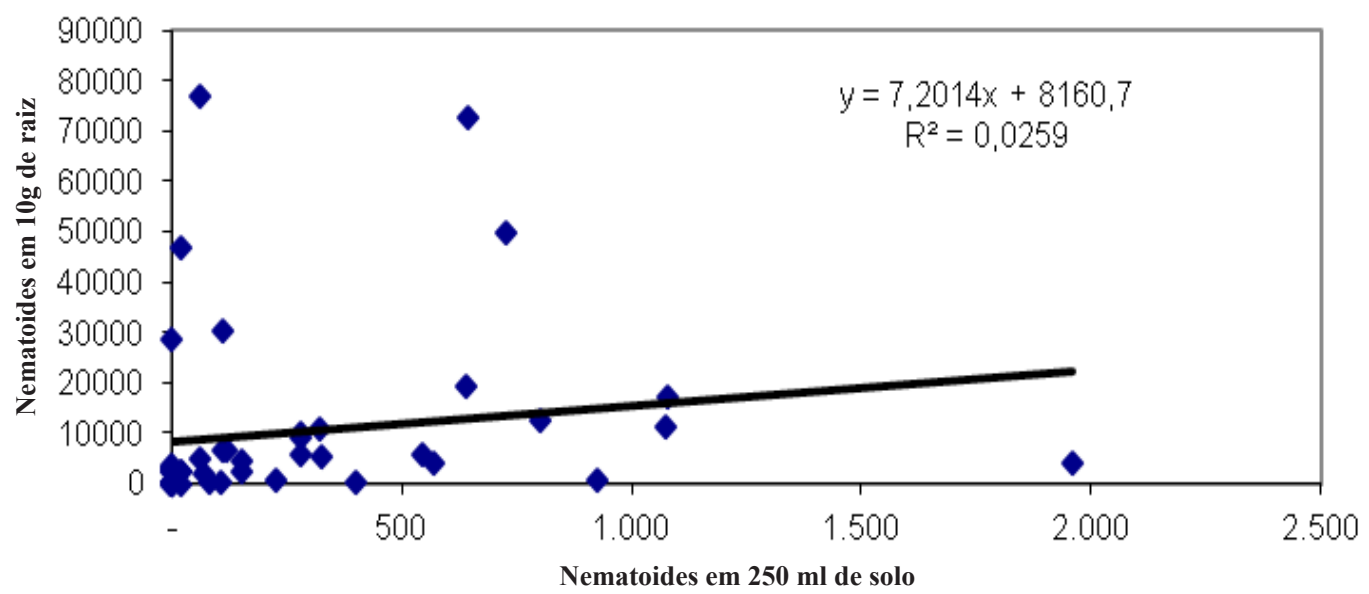

Figura 3. Correlação entre o número de juvenis de Tylenchulus semipenetrans encontrados em 10 gramas de raiz e $250 \mathrm{ml}$ de solo, amostras coletadas em setembro de 2011, Botucatu - SP. 


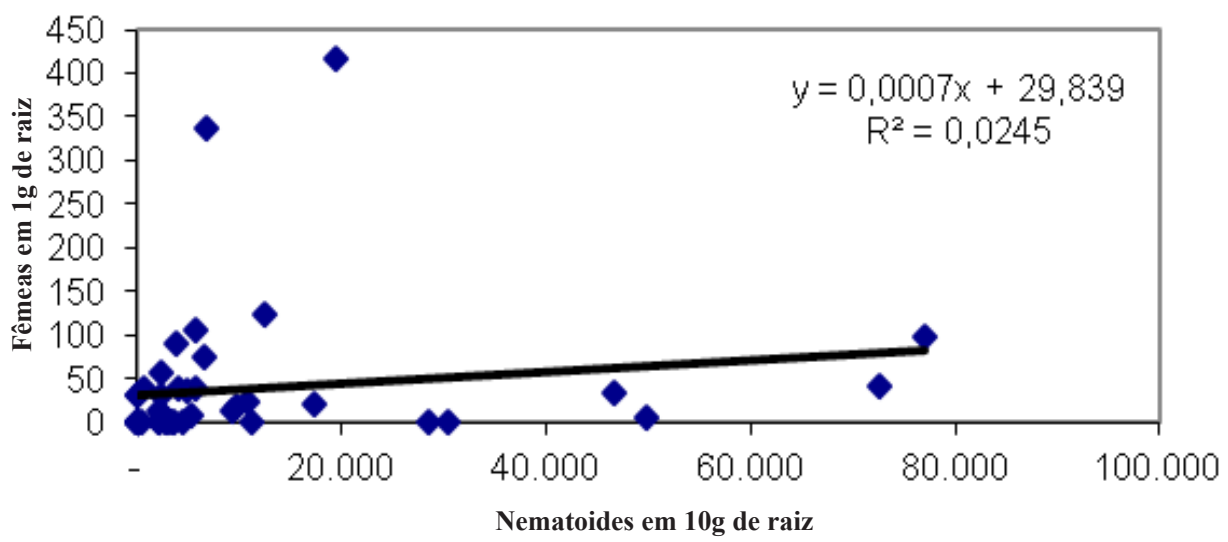

Figura 4. Correlação entre o número de fêmeas de Tylenchulus semipenetrans em 1 grama de raiz e o número de juvenis em 10 gramas de raiz , amostras coletadas em setembro de 2011, Botucatu - SP.

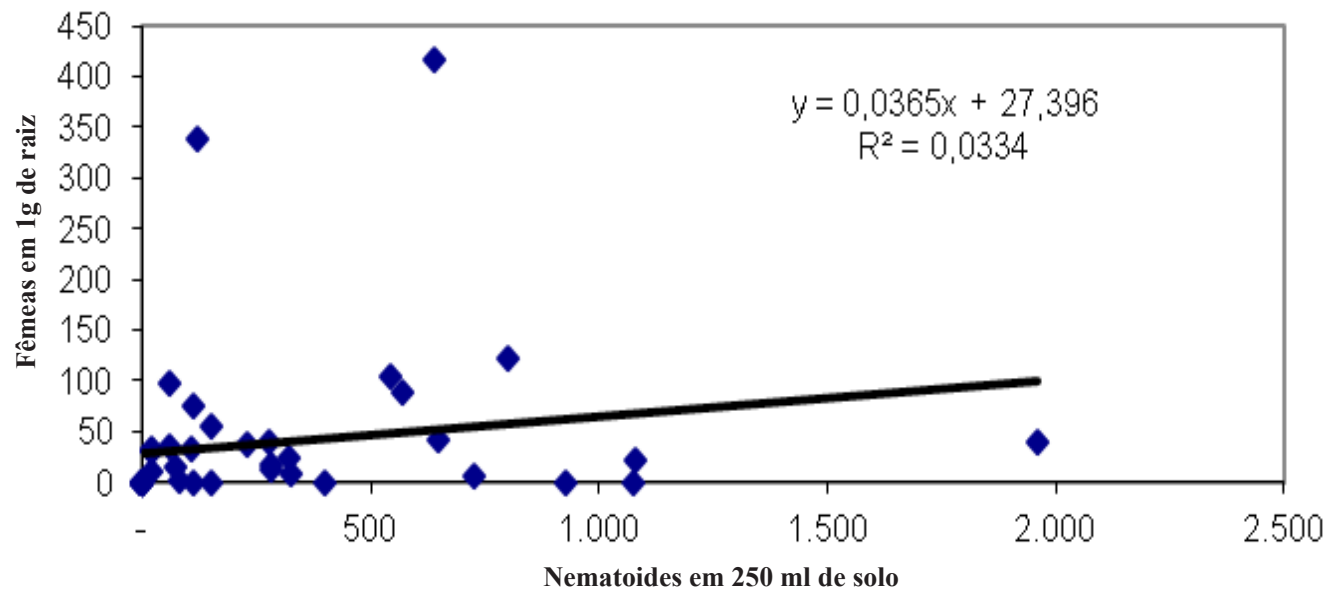

Figura 5. Correlação entre o número de fêmeas de Tylenchulus semipenetrans em 1 grama de raiz e o número de juvenis em 250 ml de solo, amostras coletadas em setembro de 2011, Botucatu - SP.

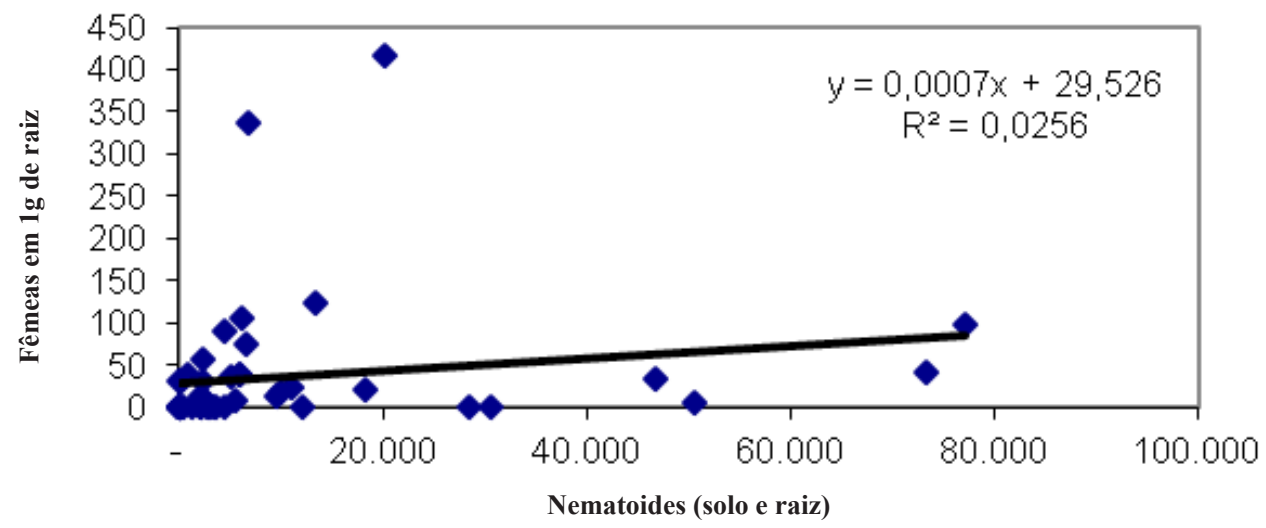

Figura 6. Correlação entre o número de fêmeas de Tylenchulus semipenetrans em 1 grama de raiz e a soma de juvenis em 10 gramas de raiz e 250 $\mathrm{ml}$ de solo, amostras coletadas em setembro de 2011, Botucatu - SP. 


\section{CONCLUSÃO}

A melhor variável para determinar a população de T. semipenetrans em campo é o número de juvenis por 10 gramas de raízes.

\section{AGRADECIMENTOS}

Ao Sr. Dirceu Bovi e toda a equipe da fazenda São Gabriel, Botucatu - SP.

\section{REFERÊNCIAS BIBLIOGRÁFICAS}

1. Campos, A.S. Distribuição dos nematóides-chave do citros no Estado de São Paulo e estudo morfométrico comparativo de cinco populações anfimíticas de Pratylenchus sp. de citros e uma de cafeeiro com duas de $\boldsymbol{P}$. coffeae. 2002. 65 f. (Dissertação de Mestrado - Entomologia Agrícola) - Faculdade de Ciências Agrárias e Veterinárias - Universidade Estadual Paulista, 2002.

2. Cohn, E. The citrus nematode, Tylenchulus semipenetrans Cobb, as a pest of citrus in Israel. Proceedings of the First International Citrus Symposium, Riverside, v. 2, p.1013-1017, 1969.

3. Coolen, W.A.; D'herde, C.J. A method for the quantitative extraction of nematodes from plant tissue. Ghent: State Agricultural Research Center, 1972. $77 \mathrm{p}$.

4. Daykin, M.E.; Hussey, R.S. Staining and histopathological techniques in nematology. In: Barker, K.R.; Carter, C.C.; Sasser, J.N. (ed). An advanced treatise on Meloidogyne. Releigh: North Carolina State University
Graphics, 1985 , p. 39-48.

5. Duncan, L. W.; Cohn, E. Nematode parasites of citrus. In: Luc, M., Sikora, R.A. Bridge, J. (ed). Plant parasitic nematodes in subtropical and tropical agriculture. Wallingford: CAB International, 1990, p. 321-346.

6. Duncan, L.W. Nematode parasites of citrus. In: Luc, M., Sikora, R.A. Bridge, J. (ed). Plant parasitic nematodes in subtropical and tropical agriculture. Wallingford: CAB International, 2005. p. 437-466.

7. Hunt, D.J.; Luc. M.; Manzanilla-López,H. Identification, Morphology and Biology of Plant Parasitic Nematodes . In: Luc, M., Sikora, R.A. Bridge, J. (ed). Plant parasitic nematodes in subtropical and tropical agriculture. Wallingford: CAB International, 2005. p. 11-52.

8. Jenkins, W.R. A rapid centrifugal-flotation technique for separating nematodes from soil. Plant Disease Reporter, v.48, p.692-695, 1964.

9. Philis, J. Yield loss assessment caused by the citrus nematode Tylenchulus semipenetrans on Valencia oranges in Cyprus. Nematologia Mediterrânea, Bari, v.17: p.5-6, 1989.

10. Santos J.M.; Campos, A.S.; Aguilar-Vildoso, C.I.. Nematoides dos citros. In: Mattos Junior, D.; J.D. Negri,; R.M. Pio; J. Pompeu Junior. (ed) Citros. Campinas: Instituto Agronômico/Fundag, 2005. p. 605-628.

11. Setzer, J. Atlas climático e ecológico do Estado de São Paulo. São Paulo: Centrais Elétricas de São Paulo, Comissão Interestadual da bacia Paraná Uruguai. 1966. 61p.

12. Sorribas, F. J. Verdejo-Lucas, S.; Forner, J. B.; Alcaide, A.; Pons, J.; Ornat, C. Seasonality of Tylenchulus semipenetrans Cobb and Pasteuria sp. in citrus orchards in Spain, College Park, v. 32, p. 622-632, 2000 Supplement.

13. Westerdahl, B. B. Citrus nematodes. UC management guidelines for nematodes on citrus, 2000. Disponível em $<$ http://www.ipm.ucdavis.edu $>$. Acesso em: 30 nov. 2012. 